\title{
Reliability of Clinical Rating Scale in Evaluation of Head Control in Children With Cerebral Palsy
}

\author{
Adamu Yakubu Abdullahi ${ }^{1}$, Auwal Abdullahi ${ }^{2}$
}

\begin{abstract}
Introduction The clinical rating scale for head control assesses control of head/neck in children with neurological conditions. Head control is important for activities of daily living and quality of life in children.

Objectives The aim of the study was to determine the intra-rater and inter-rater reliability of the scale in children with Cerebral Palsy.

Method The study was a cross-sectional study approved by Research ethics committees of Kano State Ministry of Health and Aminu Kano Teaching Hospital involving children with CP. Three independent raters assessed the children using Clinical Rating Scale for Head Control at two different times, and the intra-rater and inter-rater reliabilities were analyzed using kappa statistics and Bland-Altman analysis.

Results Fifty children with CP with mean age, $24.17 \pm 12.17$ months participated in the study. The result of the study showed that there were very good agreement in all the test positions for the three raters and between the first and the second ratings and in all the test positions between the three raters respectively $(k>0.8)$. Similarly, there was no proportional bias between ratings in 24 of the measurements $(p>0.05)$.

Conclusion Clinical rating scale for head control seems to be a reliable instrument. Thus, it can be used to monitor the progress of rehabilitation in CP patients to help improve their quality of life.
\end{abstract}

doi.org/10.29102/clinhp.21003

\section{About the AUTHORS}

1) Department of Physiotherapy, National Hospital, Abuja, Nigeria

2) Department of Physiotherapy, Bayero University, Kano, Nigeria

Contact: Auwal Abdullahi aabdullahi.pth@buk.edu.ng

\section{Introduction}

Cerebral Palsy (CP) is a group of movement and posture disorders as a result non-progressive brain damage which occurs prenatal, perinatal and postnatally $(1 ; 2)$. The disorders are often accompanied by disturbances of sensation, perception, cognition, communication, and behaviour, by epilepsy, and by secondary musculoskeletal problems (2-4). Cerebral Palsy has been reported to have a worldwide prevalence of 2 per 1000 live births (5). In Nigeria similarly, CP accounts for $42.2 \%$ of all the neurological cases reported in hospitals in Kano (6); and it accounts for $15.4 \%$ and $50.3 \%$ of neurological cases in hospitals (7). Thus, $\mathrm{CP}$ is an important public health concern; and therefore measures are needed to be taken to promote the health of children with $\mathrm{CP}$.

One of the consequences of $\mathrm{CP}$ that requires immediate attention in order to
Submitted: $\quad 9$ May 2018 Revision submitted: 17 November 2020 Accepted: 18 December 2020 Published online: 11 February 2021

promote the health of children with $\mathrm{CP}$ is poor or loss of neck control. Neck control is the ability to keep the head aligned with respect to gravity $(4 ; 8,9)$. It has been reported to be one of the early signs of delayed milestone (10). The problems with neck control in children with $\mathrm{CP}$ can often lead other delayed milestones such as inability to sit, stand and walk. These activities are essential for independence in activities of daily living and eventually quality of life of the child. Consequently, training for head control is a top most priority in children with CP (11). However, for an effective rehabilitation for neck control, a careful assessment and physical examinations are required. These assessment and physical examinations can be of great value to the physiotherapist in clinical practice, to identify problems and exchange of communication in research, and to monitor progress during management (12). 
We searched the literature in PubMED without any limits. From the literature, there are many scales such as the Peabody developmental motor scale II (PDMS-GM), Alberta infant motor scale (AIMS), Gross motor function measure (GMFS) and clinical rating scale for head control used for the assessment of gross motor function including neck control and fine motor control in children with CP $(13 ; 15 ; 16)$. The PDMS-GM is rated on a three point scale; however, it has been observed that, it is difficult to assign a score of one, probably due to very vague and subjective assignment criteria $(17 ; 18)$. In addition, the scale is not responsive, especially as regards to infants (13). In contrast, the AIMS is predominantly used for infants, and it has limitation in children 15 months old (14). Furthermore, the GMFM has been argued to have limited applicability as well since its use requires computer software and intensive training (16). Therefore, a more easy to use, objective and reliable scale for the assessment of head control in children with CP is needed.

Consequently, the clinical rating scale for head control is designed to assess head control in children with neurological impairment or delayed development, using three testing positions - prone, supine and supported sitting, to evaluate integrity of muscle strength, postural control against gravity, body movement and dynamic stability (15). Both the prone and supported sitting positions are rated on a 5 point scale (o-4); whereas, the supine position is rated on a 4 point scale (o-3). However, the psychometric properties of the scale have not been well studied as only one study with relatively small sample size examined the inter-rater reliability of the scale (15). The aim of this study is to determine both the inter-rater and intra-rater reliability of the scale using a larger sample size and a more robust statistics. This may help in improving the use of the scale in the clinic and enable clinicians know what to do in order to improve the quality of life of children with $\mathrm{CP}$. This is because there are many children with CP in Kano where the study was carried out $(6 ; 19)$

\section{Method}

\section{Study design and participants}

The study design was a cross-sectional study (repeated measures design) aimed at determining the intra-rater and inter-rater reliability of clinical rating scale for head control in children with CP. The study was approved by research ethics committees of Kano State Ministry of Health (MOH/Off/797/T.I/138) and Aminu Kano Teaching Hospital (AKTH/MAC/SUB/12A/P-3/ V11833). The population of the study was children diagnosed with CP attending outpatient physiotherapy de- partments at Aminu Kano Teaching Hospital (AKTH), Hasiya Bayero Paediatric Hospital (HBPH) and Murtala Muhammad Specialist Hospital (MMSH) in Kano metropolis. Outpatient clinics were used because children with CP are managed in the outpatient clinics in Nigeria where they are mostly seen routinely once in a week or two weeks. The inclusion criteria used were: children with CP aged between 6 months and $\leq 4$ years, and those children whose parents or caregivers gave consent to participate in the study. However, participants were excluded from the study if they had hydrocephalus.

\section{Sample size estimation}

We used a sample of 50 children with $\mathrm{CP}$ which is about twice the sample used in a previous study (15). The sampling technique used was convenience sampling.

\section{Data collection instruments}

The data collection instruments used in the study include the demographic data sheet and clinical rating scale for head control. The clinical rating scale for head control was designed to evaluate head control, and it includes the components of integrity of muscle strength, postural control against gravity, body movement and dynamic stability, using three testing positions: prone, supine and supported/recline sitting (15). It evaluates and grades quality of response using a 5 point ordinal scale (for supine and supported sitting position) and 4 point ordinal scale (for prone position). According to the author, the reliability of the scale was determined using kappa statistics and was found to be moderate to high for supine ( $\mathrm{k}=0.61,0.43$ and 0.49 respectively) and recline sitting positions $(\mathrm{k}=0.6,0.59$ and $0.53 \mathrm{re}-$ spectively), and low for prone position (0.51, 0.35 and 0.16 respectively) for the 3 raters in the study with 38 participants. Reliability is classified as poor when $\mathrm{k}<$ 0.20 , fair when $\mathrm{k}$ is between 0.21 and 0.40 , moderate when $\mathrm{k}$ is between 0.41 and 0.60 , good when $\mathrm{k}$ is between 0.61 and 0.80 when very good when $\mathrm{k}$ is between 0.81 and 1.00 (20).

\section{Data collection procedure}

Three independent blinded raters A, B and C, who are Physiotherapists with at least 1 year post graduation experience, received prior training on how to collect data using the clinical rating scale for head control. The data was collected at baseline and a week after. We thought one week is a time long enough to prevent the first assessment to influence the second assessment. All children were placed on a couch in prone, supine and supported sitting positions during the assessments. See appendix A for the details of the clinical rating scale for head control. All the raters assessed head control of the 


\section{Research and Best Practice}

available children on the first day and a week later with an interval of 10 minutes per rater. All raters were blinded from each others' assessments (by ensuring only the rater was in the assessment room) and the aim of the study. Data was collected between August 8th 2016 and November 15th 2016.

\section{Data analysis}

The data collected was analyzed for intra-rater and inter-rater reliability using non-parametric statistics of Kappa to determine agreement between two measurements and Bland-Altman analysis to help graphically visualize the agreement and determine if there is or there is no proportional bias between two measurements. The Bland-Altman involves carrying out one-sample t-test to determine if there is no any significant difference between the two measurements. If there was no significant difference between the two measurements, a Bland-Altman plot was constructed. Finally, linear regression analysis was carried out to determine if there was any proportional bias in the two measurements. All statistical analyses were carried out using Statistical Package for Social Sciences (SPSS) version 20.0, with alpha level set at 0.05 .

\section{Results}

\section{Characteristics of the Study Participants}

There were 50 children with $\mathrm{CP}$ with age range (6-48 months) who participated in the study. See figure 1 for the study flowchart. In addition, there were equal number of females and males. The summary of the characteristics of the study participants is presented in table 1.

\section{Intra-rater Reliability}

In all the test positions (prone, supine and supported/ recline sitting) for the all the raters (A, B and $\mathrm{C}$ ), there very good agreements between the first and the second ratings, Cronbach's alpha value between 0.8 and 1.00. See table 2 for the details of the results. However, the-

Figure 1. The Study Flowchart

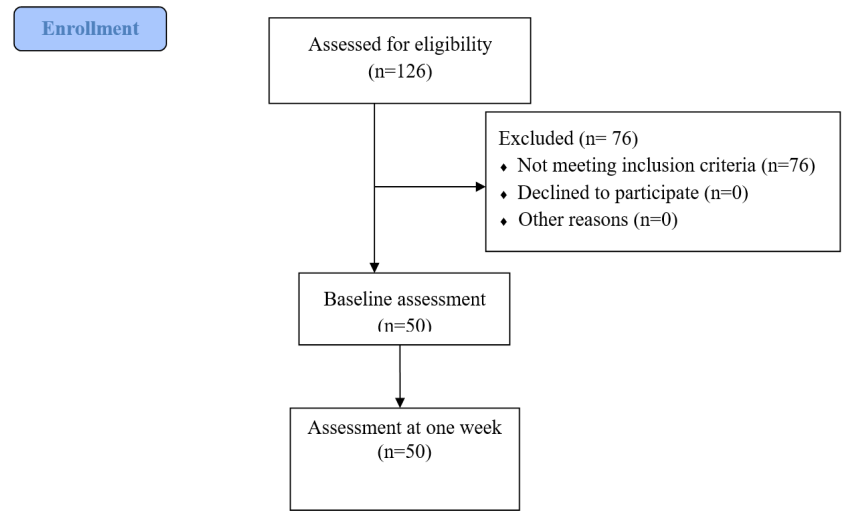

Table 1. Characteristics of the study participants

\begin{tabular}{|c|c|c|}
\hline Variables & n (\%) & Mean $\pm S D$ \\
\hline Age & & $24.17 \pm 12.17$ \\
\hline \multicolumn{3}{|l|}{ Gender } \\
\hline Male & 25 (50\%) & \\
\hline Female & 25 (50\%) & \\
\hline \multicolumn{3}{|l|}{ Types of CP } \\
\hline Spastic & 21 (42\%) & \\
\hline Dyskinetic & $5(10 \%)$ & \\
\hline Ataxic & $5(10 \%)$ & \\
\hline Hypotonic & 19 (38\%) & \\
\hline \multicolumn{3}{|l|}{ Aetiology } \\
\hline Neonatal Jaundice & $14(28 \%)$ & \\
\hline Birth Asphyxia & $28(56 \%)$ & \\
\hline Prematurity & $8(16 \%)$ & \\
\hline \multicolumn{3}{|l|}{ Ambulation Status } \\
\hline Ambulant & $6(12 \%)$ & \\
\hline Non-Ambulant & $44 \quad(88 \%)$ & \\
\hline
\end{tabular}

re was no proportional bias in only ratings of rater $\mathrm{B}$ in prone (Beta $=-0.025, p=0.180$; see figure 2), rater $\mathrm{C}$ in prone (Beta $=0.025, \mathrm{p}=0.180$; see figure 3 ), rater $\mathrm{A}$ in supine (Beta $=-0.027, \mathrm{p}=0.252)$, rater $\mathrm{B}$ in supine $(\mathrm{Beta}=-0.014, \mathrm{p}=0.734)$, rater $\mathrm{C}$ in supine $($ Beta $=0.031$, $\mathrm{p}=0.307)$, rater $\mathrm{A}$ in sitting (Beta $=-0.018, \mathrm{p}=0.354$ ), rater $\mathrm{B}$ in sitting (Beta $=-0.008, \mathrm{p}=0.792$ ) and $\mathrm{C}$ rater in sitting (Beta=-0.016, $\mathrm{p}=0.671)$.

\section{Inter-rater Reliability}

Similarly, there were very good agreements between the three raters (A, B and C) in all the test positions (prone, supine and supported/recline sitting). See table 3 for the details of the results. In addition, there was no proportional bias in prone position between rater $\mathrm{A}$ and rater $\mathrm{B}(\mathrm{Beta}=-0.09, \mathrm{p}=0.692)$ and rater $\mathrm{A}$ and rater $\mathrm{C}$ (Beta=-0.09, $\mathrm{p}=0.692$ ) in the first measurement; and between rater $\mathrm{A}$ and rater $\mathrm{B}(\mathrm{Beta}=-0.014, \mathrm{p}=0.292)$ and rater $\mathrm{A}$ and rater $\mathrm{C}(\mathrm{Beta}=-0.014, \mathrm{p}=0.292)$ in the second measurement.

\begin{tabular}{lccc}
\multicolumn{2}{l}{ Table 2. Intra-rater reliability of the clinical rating scale for head control } \\
\hline Position & \multicolumn{3}{c}{ Cronbach's Alpha } \\
\hline \multirow{4}{*}{ Rater A } & Rater B & Rater C \\
Prone & 0.992 & 0.996 & 0.996 \\
Supine & 0.993 & 0.981 & 0.989 \\
Supported Sitting & 0.996 & 0.989 & 0.983
\end{tabular}




\section{Research and Best Practice}

Figure 2. Bland-Altman Plot for the Ratings of Rater B in Prone

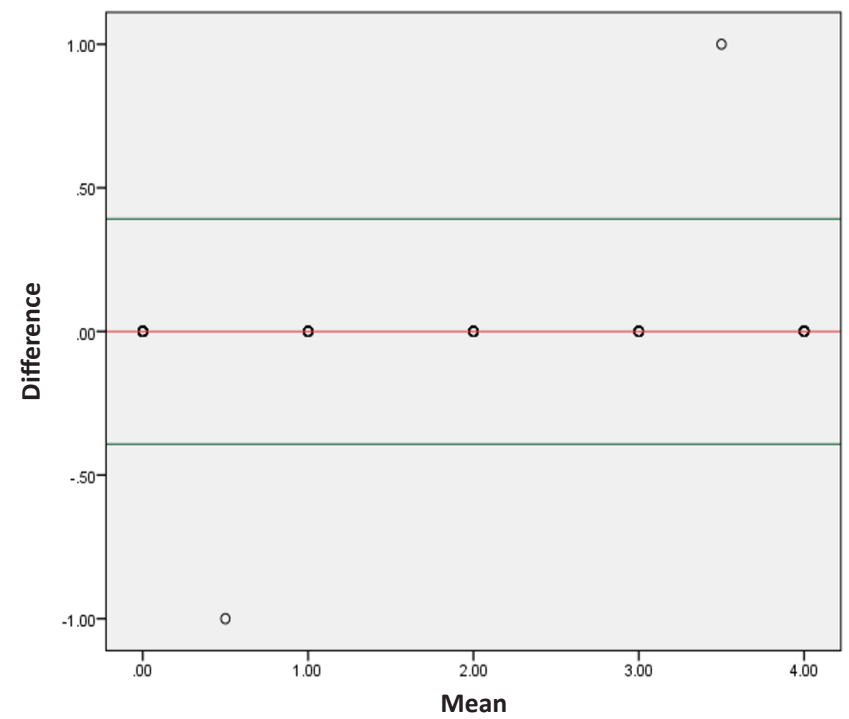

In supine position, there was no proportional bias between rater $\mathrm{A}$ and rater $\mathrm{B}$ (Beta $=-0.043, \mathrm{p}=0.275$ ), rater $\mathrm{A}$ and rater $\mathrm{C}($ Beta $=-0.011, \mathrm{p}=0.739)$ and rater $\mathrm{B}$ and rater $\mathrm{C}(\mathrm{Beta}=-0.031, \mathrm{p}=0.428)$. Similarly, there was no proportional bias between rater $\mathrm{A}$ and rater $\mathrm{B}(\mathrm{Beta}=0.057, \mathrm{p}=0.096)$, rater $\mathrm{A}$ and rater $\mathrm{C}(\mathrm{Beta}=0.070, \mathrm{p}=0.065)$ and rater $\mathrm{B}$ and rater $\mathrm{C}$ (Beta $=0.013, p=0.662$ ) in the second measurements.

In sitting, there was no proportional bias between rater $\mathrm{A}$ and rater $\mathrm{C}(\mathrm{Beta}=-0.035, \mathrm{p}=0.191)$, rater $\mathrm{B}$ and rater $\mathrm{C}(\mathrm{Beta}=-0.023, \mathrm{p}=0.579)$. Similarly, there was no proportional bias between rater $\mathrm{A}$ and rater $\mathrm{B}$ (Beta $=-0.003, \mathrm{p}=0.942)$, rater $\mathrm{A}$ and rater $\mathrm{C}$ (Beta=$0.033, \mathrm{p}=0.305)$ and rater $\mathrm{B}$ and rater $\mathrm{C}($ Beta $=-0.003$, $\mathrm{p}=0.383)$ in the second measurements.

\section{Discussion}

This study intended to look at the intra-rater and inter-rater reliability of clinical rating scale for head control developed by Chavan to grade the quality of head/ neck control in children with motor or other neurological impairments including cerebral palsy, motor delay,
Figure 3. Bland-Altman Plot for the Ratings of Rater C in Prone

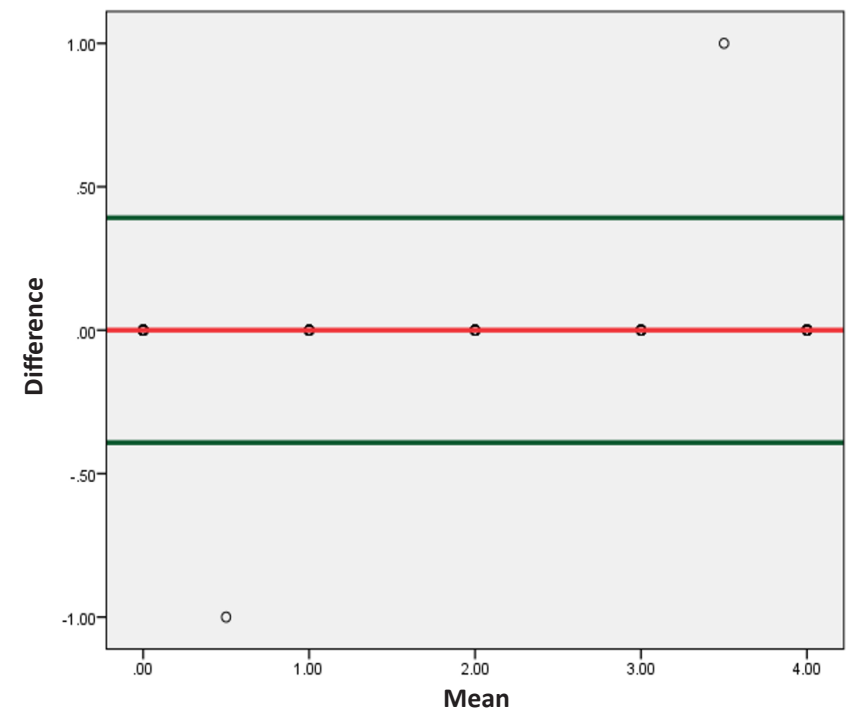

Down's syndrome and hydrocephalus (15). According to Chavan, the pilot study for the creation of the scale needs further validation on larger samples as well as establishing the intra-rater reliability, and inter-rater reliability before the scale could be ascertained to be applicable for clinical use (15). Therefore, this study included a sample of 50 participants of purely CP patients undergoing rehabilitation in the delimited hospitals within Kano metropolis to determine intra- and inter-rater reliability of the scale. According to Craig and James, for objective criterion reference testing (CTR), the most useful types of reliability studies are test-retest reliability, parallel forms reliability, and decision consistency (21). In this present study, the scores for test and retest were examined for the three test positions for all the three raters (A, B and C).

The result of the study showed a very good agreement for both the intra-rater and inter-rater reliabilities in all three test positions for all the raters. In addition, in 24 of the measurements, there were no proportional biases, indicating robustness of the agreement. Meanwhile, a previous inter-rater study found low

Table 3. Inter-rater reliability of the clinical rating scale for head control

\begin{tabular}{|c|c|c|c|c|c|c|}
\hline \multirow[t]{3}{*}{ Position } & \multicolumn{6}{|c|}{ Cronbach's Alpha } \\
\hline & \multicolumn{3}{|c|}{ First measurement } & \multicolumn{3}{|c|}{ Second measurement } \\
\hline & $\begin{array}{l}\text { Rater A versus } \\
\text { Rater B }\end{array}$ & $\begin{array}{l}\text { Rater } A \text { versus } \\
\text { Rater C }\end{array}$ & $\begin{array}{l}\text { Rater B versus } \\
\quad \text { Rater C }\end{array}$ & $\begin{array}{l}\text { Rater } A \text { versus } \\
\text { Rater B }\end{array}$ & $\begin{array}{l}\text { Rater } A \text { versus } \\
\quad \text { Rater } C\end{array}$ & $\begin{array}{c}\text { Rater B versus } \\
\text { Rater C }\end{array}$ \\
\hline Prone & 0.994 & 0.994 & 1.000 & 0.998 & 0.998 & 1.000 \\
\hline Supine & 0.982 & 0.986 & 0.981 & 0.986 & 0.982 & 0.989 \\
\hline
\end{tabular}


agreement between the raters for prone position, and moderate to good agreements for supine and supported sitting positions of the clinical rating scale for head control among 3 raters in children with $\mathrm{CP}$ and other childhood neurological conditions (15). However, in his study, there were only 28 subjects with mean age $17.60 \pm 12.63$ months, out of which only 17 were diagnosed of CP. Possibly, having different conditions and children with relatively younger age, may account for the difference in his findings with those of the present study.

Although, prior to the present study, there seemed to be only one study assessing head control in children using clinical rating scale for head control (15); assessing the psychometric properties of an instrument such as inter-rater and intra-rater reliability is important criterion test referencing (22). Consequently, the present study looked at both inter-rater and intra-rater reliability of the clinical rating scale for head control and the results obtained showed that, the scale can be adjudged to be reliable for clinical use. Therefore, the impact of these findings is that, this simple and affordable scale can be used in the clinics for the assessment of head control in children with CP. However, one of the limitations of this study is that we did not determine the construct and concurrent validity of the scale. Nonetheless, further studies on the validity of the scale and its sensitivity to detect changes during neurorehabilitation needs to be done in order to increase the strength of its clinical applicability. This is because increasing clinical use of an instrument may help clinicians to detect problems and design effective rehabilitation in order to promote the health and improve the quality of children with CP.

\section{Contributors:}

Conception and design: AAY, AA.

Acquisition of data: AAY.

Analysis and interpretation of data: AA.

Drafting, revising and final approving of the article: AA, AY.

Competing interests: None declared.

Funding: No funding.

Patient consent: Signed written informed consents were provided by the parents or caregivers of the children included in the study.

Ethics approval: The study was approved by research ethics committees of Kano State Ministry of Health (MOH/ Off/797/T.I/138) and Aminu Kano Teaching Hospital (AKTH/MAC/SUB/12A/P-3/V11833).

\section{References}

(1) Keith RCM, McKenzie ICK, Polani PE. Memorandum on Terminology and Classification of 'Cerebral Palsy.' Cereb Palsy Bull. 1959;1:27-35. doi:10.1111/i.1469-8749.1959.tb08073.x.

(2) Rosenbaum P, Paneth N, Leviton A, Goldstein M, Bax M. A Report: The Definition and Classification of Cerebral Palsy. Dev Med Child Neurol. 2007;109:8-14.

(3) Bax MCO. Terminology and Classification of Cerebral Palsy. Dev Med Child Neurol. 1964;6:295-307. doi:10.1111/j.1469-8749.1964.tb10791.x.

(4) Bax M, Goldstein M, Rosenbaum P, et al. Executive Committee for the Definition of Cerebral Palsy, Proposed Definition and Classification of Cerebral Palsy. Dev Med Child Neurol. 2005;47:571-6. doi: 10.1017/ s001216220500112x.

(5) Odding E, Roebroeck ME, Stam HJ. The Epidemiology of Cerebral Palsy: Incidence, Impairments and Risk Factors. Disabil Rehabil. 2006;28:183-191. doi:10.1080/09638280500158422.

(6) Belonwu RO, Gwarzo GD, Adeleke SI. Cerebral Palsy in Kano, Nigeria - a Review. Niger J Med. 2009;18:186-9. doi:10.4314/njm.v18i2.45062.

(7) Ogunlesi T, Ogundeyi M, Adekanmbi F, Fetuga B, Ogunforowa O, Olowu A. Socio-Clinical Issues in Cerebral Palsy in Sagamu, Nigeria. S Afr J child health 2008;2:120-4.

(8) Brenneman SK (1999). Tests of infant and child development. In: Tecklin JS, editor. Pediatric Physical Therapy 9th ed. Philadelphia: Lippincott, Williams \& Wilkins. pp28-70.

(9) Rosenbaum PL, Walter SD, Hanna SE. Prognosis for Gross Motor Function in Cerebral Palsy Creation of Motor Development Curves. JAMA 2002; 288:1357-1363. doi:10.1001/jama.288.11.1357.

(10) Scherzer A, Tscharnuter I (1990). Early diagnosis and therapy in cerebral palsy : a primer on infant developmental problems (2nd edn). New York: M. Dekker.

(11) Mital MA, Belkin SC, Sullivan MA. An Approach to Head, Neck and Trunk Stabilization and Control in Cerebral Palsy by Use of the Milwaukee Brace. Dev Med Child Neurol. 1976;18:198-203. doi:10.1111/j.1469-8749.1976. tb03629.x.

(12) Sæther R, Jørgensen L. Intra- and Inter-Observer Reliability of the Trunk Impairment Scale for Children With Cerebral Palsy. Res Dev Disabil. 2011;32:727-39. doi: 10.1016/i.ridd.2010.11.007.

(13) Palisano RJ, Kolobe M, Haley SM. Validity of the Peabody Developmental Gross Motor Scale as an Evaluative Measure of Infants Receiving Physical Therapy. Phys Ther. 1995;75:939-951. doi: 10.1093/pti/75.11.939. (14) Piper MC, Pinell LE, Darrah J, Maguire T, Byrne PJ. Construction and Validation of the Alberta Infant Motor Scale (AIMS). Can J Public Health 1992;83:S46-50.

(15) Chavan, SR. Clinical Rating Scale for Head Control - Pilot Study. Indian J Occup Ther. 2008;XXXIX:59-64.

(16) Russell DJ, Rosenbaum PL, Avery LM, Lane M. Gross Motor Function Measure (GMFM-66 and GMFM-88) User's Manual. London, United Kingdom: Mac Keith Press; 2002.

(17) Hinderer KA, Richardson PK, Atwater SW. Clinical Implications of the Peabody Developmental Motor Scales: A Constructive Review. Phys Occup Ther Pediatr. 1989;9:81-106.

(18) Gebhard AR, Ottenbacher KJ, Lane SJ. Interrater Reliability of the Peabody Developmental Motor Scales: Fine Motor Scale. Am J Occup Ther. 1994;48:976-81. doi: 10.5014/ajot.48.11.976.

(19) Badaru UM, Ma'aruf IS, Ahmad RY, Lawal IU, Usman JS. Prevalence and Pattern of Paediatric Neurological Disorders Managed in Outpatient Physiotherapy Clinics in Kano. BAJOPAS 2009;12:201-6.

(20) Jeng SF, Tsou-Yau KI, Chen LC. Alberta Infant Motor Scale: Reliability and Validity When Used on Preterm Infants in Taiwan. Phys Ther. 2000;80:168-78.

(21) Altman DG, Bland JM. Measurement in Medicine: The Analysis of Method Comparison Studies. Statistician. 1983;32:307-17. doi:10.2307/2987937.

(22) Craig SW, James AW (2013). An Instructor's Guide to Understanding Test Reliability, Testing \& Evaluation Services University of Wisconsin 1025 W. Johnson St., \#373 Madison,WI 53706. 


\section{Research and Best Practice}

Appendix A. Clinical scale for head control (15).

\begin{tabular}{|c|c|c|c|c|c|c|c|}
\hline \multirow{2}{*}{ Position } & \multirow{2}{*}{ Grade } & \multirow{2}{*}{ Description } & \multicolumn{5}{|c|}{ Day of Adminstration } \\
\hline & & & 1 & 2 & 3 & 4 & 5 \\
\hline \multirow{5}{*}{ Prone } & 0 & Does not lift head at all. Weight bearing on the cheek/chest or on the shoulder. & & & & & \\
\hline & 1 & $\begin{array}{l}\text { An effort to raise the head results in asymmetry and/or increased extensor hypertonicity throughout the body. } \\
\text { Elbows are positioned clooser to the trunk and behind shoulders. Arms cannot be brought forward into weight } \\
\text { bearing pattern. }\end{array}$ & & & & & \\
\hline & 2 & Lifts head in prone but cannot sustain for longer duration. Cannot turn to look over shoulder. & & & & & \\
\hline & 3 & $\begin{array}{l}\text { Lifts head in prone with hyperextension of head and neck. Elevation of shoulder usually accompanies this posture } \\
\text { (i.e. decreased shoulder stability). Brings arms actively to weight bearing upon forearm and can turn to look over } \\
\text { shoulders. }\end{array}$ & & & & & \\
\hline & 4 & $\begin{array}{l}\text { No abnormal pattern observed. Keeps the head steady whilw playing with one or both hands. Movement of head is } \\
\text { possible in all the planes. }\end{array}$ & & & & & \\
\hline \multirow{4}{*}{ Supine } & 0 & On pulled to sit from supine exhibits complete head lag. (Not able to keep the head in midline). & & & & & \\
\hline & 1 & Able to keep the head in midline but complete head lag present on being pulled to sit. & & & & & \\
\hline & 2 & On being pulled to sit initial head lag present. However, soon aligns the head with the trunk. & & & & & \\
\hline & 3 & $\begin{array}{l}\text { No abnormal pattern observed. On being pulled to sit initiate and sustain lifting of head in supine. Keeps the head } \\
\text { steady in midline. }\end{array}$ & & & & & \\
\hline \multirow{5}{*}{$\begin{array}{l}\text { Supported } \\
\text { sitting and/or } \\
\text { on reclining. }\end{array}$} & 0 & Head wobbles on either side. Requires full support to prevent head drop. & & & & & \\
\hline & 1 & Head remains in midline position for a brief interval of time. Intermittent support required preventing head drop. & & & & & \\
\hline & 2 & $\begin{array}{l}\text { On reclining at } 15-20 \text { degrees maintains head in midline. However, cannot sustain head in midline beyond } 45 \\
\text { degrees or reclining. }\end{array}$ & & & & & \\
\hline & 3 & $\begin{array}{l}\text { On reclining more than } 45 \text { degrees sustains head in midline. Head is steady during play or movement of the head } \\
\text { however poor dissociation between head and shoulder gridle. }\end{array}$ & & & & & \\
\hline & 4 & $\begin{array}{l}\text { No abnormal pattern observed. Keeps the head steady during play with good dissociation between head and } \\
\text { shoulder girdle. }\end{array}$ & & & & & \\
\hline
\end{tabular}

